\title{
TESOURO NACIONAL: A CRIAÇÃO DE BENS \\ CULTURAIS NA ERA MEIJI ${ }^{1}$ \\ NATIONAL TREASURY: CREATION OF CULTURAL \\ PROPERTY AT MEIJI PERIOD
}

Naoko Ando ${ }^{2}$

Resumo: O presente artigo analisa a formação do Tesouro Nacional, os bens culturais de maior importância no Japão. Sendo a sua grande maioria obras de arte, pode-se considerar que o tombamento do Tesouro Nacional representa as particularidades da política japonesa de preservação do patrimônio cultural. Dessa forma, este artigo pretende revelar o desenvolvimento do conceito de Tesouro Nacional e analisar a origem da sua particularidade, desde o início da proteção de objetos antigos até a publicação da primeira lei, ocorridos na Era Meiji.

Palavras-chave: Tesouro Nacional, bens culturais, Era Meiji, cultura japonesa, política de patrimônio cultural.

Abstract: This article analyzes the creation of the National Treasure, the most important cultural heritage in Japan. The majority of the National Treasure are art works, which represents the peculiarities of the Japanese policy of preserving cultural heritage. Therefore, this article intends to reveal the development of the National Treasury concept and analyze the origin of its particularity, from the beginning of the protection of ancient objects until the publication of the first law, occurred in the Meiji period.

Keywords: National Treasure, cultural property, Meiji period, Japanese culture, cultural heritage policy.

1 Artigo submetido em 24/05/2018 e aceito em 10/06/2018.

2 Mestre em Estudos Regionais pela Tokyo University of Foreign Studies (TUFS), Tóquio, Japão e Mestre em Língua, Literatura e Cultura Japonesa da Faculdade de Filosofia, Letras e Ciências Humanas (FFLCH) da Universidade de São Paulo (USP), São Paulo, Brasil; branaoko@gmail.com (ORCID iD http://orcid.org/0000-0002-9680-4278). 


\section{Introdução}

Nos dias atuais, podemos apreciar diversos bens culturais ou visitar e conhecer algum patrimônio cultural. No Japão, como a Figura 1 mostra $^{3}$, os museus nas principais cidades fazem frequentemente exposições especiais, reunindo bens culturais, chamados de Tesouro Nacional (Kokuhô) ou Bens Culturais Importantes (Jûyô Bunkazai), conceitos que são muito comuns entre o povo japonês. Também existem vários templos budistas e xintoístas que possuem esculturas, pinturas e construções tombadas em todo o país, sendo foco de turismo para quem procura conhecer história e arte japonesa.

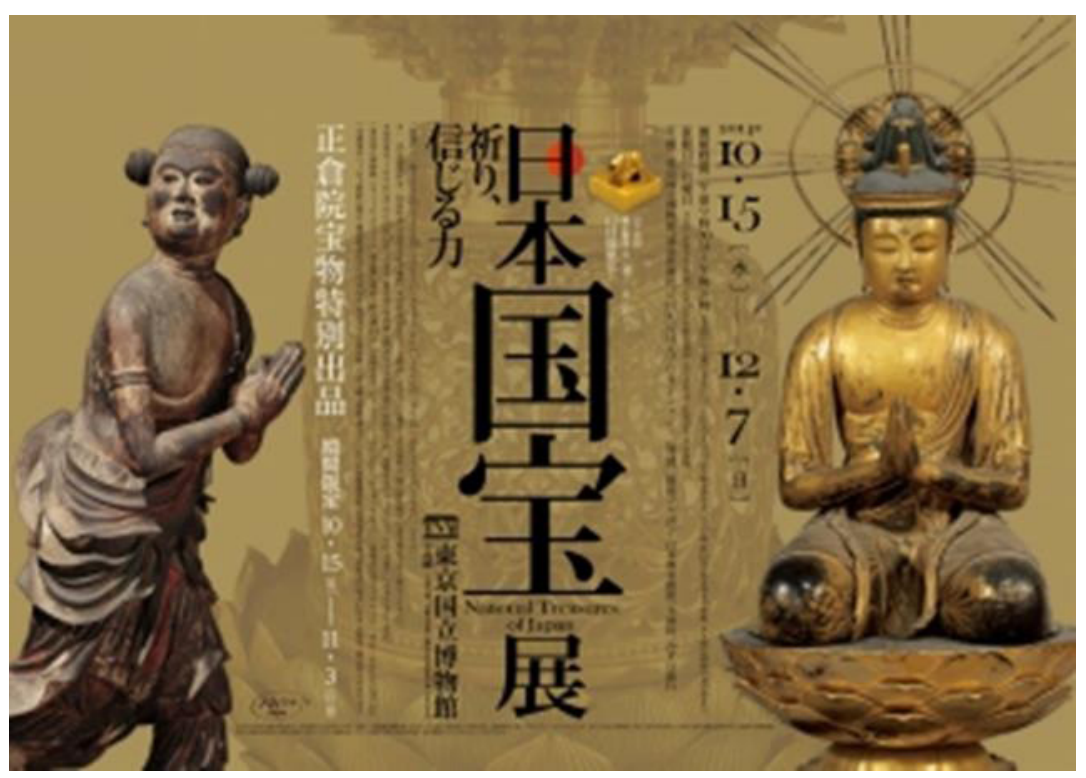

Figura 1. Pôster de exposição "Tesouro Nacional do Japão - Oração e a força de fé" Fonte: Tokyo Nacional Museum https://www.tnm.jp/modules/r_free_page/index.php?id=1648\#top

No entanto, essa oportunidade de observar as obras religiosas é uma tendência relativamente contemporânea. Muitas esculturas que hoje podemos encontrar nos museus, até a Era Meiji, estavam preservadas no fundo de santuários e recebiam apenas

3 Pôster da exposição realizada no Museu Nacional de Tóquio em 2014, que mostra duas estátuas budistas consideradas Tesouro Nacional. O evento reuniu cerca de 120 peças de Tesouro Nacional e recebeu mais de 300.000 visitantes durante dois meses.

4 Trata-se de duas classificações de tombamento. Entre os objetos tombados como Bens Culturais Importantes, os reconhecidos pelo seu valor de extrema importância são selecionados e denominados de Tesouro Nacional. 
visitas de religiosos. Em outros casos, estavam trancadas em altares como estátuas secretas por sua alta divindade. O tombamento de objetos religiosos possibilitou o acesso ao público devido à política de preservação que visa ao aproveitamento de bens tombados como meio de educação e divulgação da história e da arte do país. E a designação de Tesouro Nacional garante a maior importância dos objetos e serve como referência ao reconhecimento de valor das obras.

O objetivo deste artigo é analisar esse sistema de tombamento do Tesouro Nacional, focando na formação do seu conceito no período Meiji (1868-1912) quando foram estabelecidas as primeiras normas jurídicas sobre proteção de bens culturais no Japão.

\section{Tesouro Nacional e suas particularidades}

Há estudos que descrevem as caraterísticas da política japonesa sobre a preservação do patrimônio cultural. A maioria destaca o patrimônio imaterial, ou seja, o patrimônio intangível, conceito incluído na legislação japonesa desde 1950. Saitsu (2013), por exemplo, defende que esse conceito antecede a desmaterialização do patrimônio cultural estabelecida pela UNESCO nas últimas décadas.

Por outro lado, Ogawa (2011) admite a influência japonesa na introdução do conceito de patrimônio imaterial da UNESCO e afirma ainda que a maior caraterística da política do país é a designação do Tesouro Nacional. Segundo Ogawa, a Mona Lisa de Leonardo da Vinci, uma das obras mais conhecidas da França, não consta do inventário de bens tombados, enquanto as pinturas de Sesshu ${ }^{5}$, feitas na mesma época do século 15 a 16, são consideradas Tesouro Nacional.

A política brasileira assim como a francesa, também não adota o sistema de tombamento de obras individuais. As peças de pintura ou escultura são tombadas como conjunto de acervo ou coleção de museus e igrejas.

Tanaka, ex-presidente do Instituto Nacional de Bens Culturais de Nara também ressalta que não há uma política de preservação parecida com a do Japão, que inclui obras de arte no seu inventário de patrimônio cultural. Assim como o Gráfico 1 mostra, no Japão, a grande maioria dos bens tombados de Tesouro Nacional é peça individual, ou seja, bem móvel. Apenas $20 \%$ são bens imóveis, tais como construções históricas ou religiosas.

5 Monge e artista da Era Muromachi, mais conhecido por suas obras de Sumi-ê. 


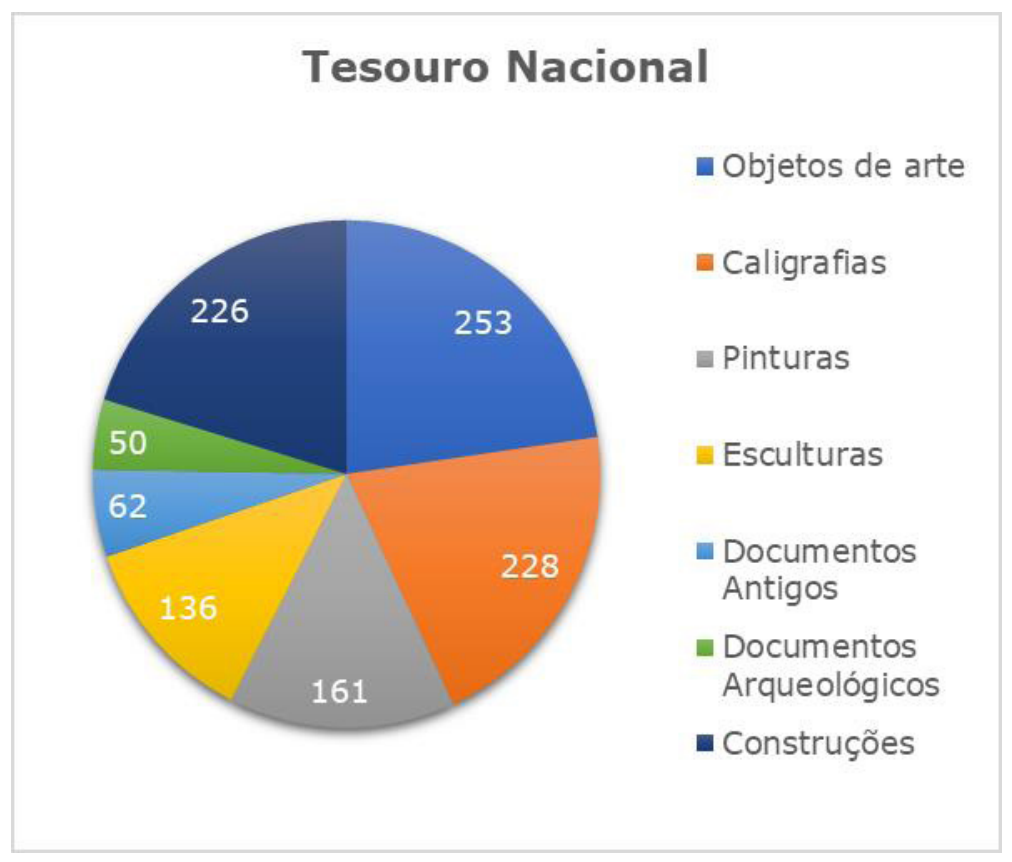

Gráfico 1. Classificação de Tesouro Nacional

Fonte: Ministério da Cultura. Elaborado pela autora a partir de dados fornecidos em $30 / 10 / 2018$

Entretanto, esses apontamentos não explicam a justificativa da particularidade do sistema japonês de preservação. Isto posto, o artigo visa analisar por qual motivo as peças artísticas se tornaram o maior foco do tombamento no Japão.

O inventário atual do Tesouro Nacional vem sendo elaborado pela legislação em vigor desde 1950. Porém seu conceito foi estabelecido anteriormente, em 1897 na Era Meiji, com a promulgação da Lei de Preservação de Templos Antigos (Koshaji Hozonhô). Como estudiosos (Tanaka e outros) apontam, foi essa lei que deu base para a política japonesa de preservação de bens culturais. Dessa forma, é válido observar o processo de formação das primeiras normas jurídicas da época para entender a particularidade do Tesouro Nacional.

\section{Início da preservação de objetos antigos}

Para entender a institucionalização da questão patrimonial, Fonseca (2009:59) explica na sua pesquisa sobre trajetória da política de patrimônio no Brasil que a noção de patrimônio se insere no projeto mais amplo de construção de 
uma identidade nacional e passa a servir ao processo de consolidação dos EstadosNações modernos. No caso do Japão, isto corresponde ao período Meiji, quando houve a grande mobilização da sociedade com o término do chamado Sakoku (política de relação estrita internacional) e a modernização consequente da abertura do país.

Com a Restauração Meiji, o país passou pela reforma dinâmica não apenas no âmbito do Estado, mas também na vida cotidiana do povo japonês sob o lema "abertura para a civilização" (Bun'mei Kaika).

Nesse ambiente da modernização do país rumo ao modelo europeu, juntamente com a ruptura do sistema feudal, muitos edifícios foram destruídos e objetos e obras antigas foram vendidos. A situação desfavorável aos monumentos históricos tornou-se irremediável quando o governo promulgou a Ordem de Separação do Budismo e do Xintoísmo (Shin'butsu Bun'ri Rei) no dia 28 de março de 1868. O objetivo dessa ordem era proibir a mistura das religiões a fim de que o país adotasse o xintoísmo como uma única religião oficial nacional. Porém essa ordem resultou no movimento violento de característica anti-budista chamado de Haibutsu Kishaku, literalmente "destruição de Buda e abandono da doutrina budista" .

Embora o movimento tenha durado somente os primeiros anos da Era Meiji, o dano espalhou-se por todo o país e foi necessária uma medida urgente para a proteção dos bens históricos e religiosos. Perante a situação, o governo Meiji publicou o Édito para a Proteção de Antiguidades e Objetos Antigos (Koki Kyûbutsu Hozon Kata) no dia 23 de maio de 1871 como segue abaixo:

Apesar da sua importância para estudar a trajetória da história e reconhecer a transição do sistema institucional e de costumes populares do tempo, os monumentos históricos e antigos, lamentavelmente, estão em plena destruição e perda devido à tendência corrente de preferir novidades e desprezar antiguidades. $^{6}$

Essa nova política obriga os templos budistas e xintoístas, assim como proprietários particulares, a realizarem inventários de bens de valor histórico conforme a lista de indicação. A lista consiste em trinta e uma categorias, como armas, artigos de rituais, ferramentas agrícolas, cerâmicas, caligrafias e pinturas, instrumentos musicais, moedas, indumentárias, brinquedos, entre outros. Pode-se notar que, para a autoridade neste momento "os objetos a serem preservados" incluem não apenas as obras artísticas, mas também os artigos relacionados com costumes e práticas da vida cotidiana do povo japonês. $\mathrm{O}$ fato implica que nessa época não havia ainda a definição do conceito de "arte", cuja importância é destacada nas políticas de patrimônio subsequentes. A proteção dos bens culturais foi realizada por seu valor histórico ou folclórico.

6 Fonte: Nacional Diet Library. http://dl.ndl.go.jp/info:ndljp/pid/787951/145. Acesso em 13/01/2018. 


\section{Reconhecimento da arte japonesa}

\subsection{Coleção e exposição de objetos}

Suzuki (2005: 50) aponta que houve grande modificação do significado de objetos antigos ao longo da Era Meiji desde que sua proteção foi inserida nos projetos do Estado. O primeiro projeto do governo Meiji em torno do assunto foi a realização de exposições (Hakuran-kai) e a criação do Museu Nacional. A partir de 1872, o Departamento de Museus (Hakubutsu-kyoku) do Ministério da Educação (Monbu-shô) realizou exposições domésticas. ${ }^{7}$ O Hakubutsu-kyoku considerava a realização de exposições como processo de criação do museu. Hisanari Machida, funcionário do departamento, estudou na Inglaterra e, assim que retornou ao Japão no início da Era Meiji, entregou ao governo um projeto para a criação de museus. O projeto do Machida era coletar os objetos antigos de diversas regiões nas exposições e guardá-los para o futuro acervo do primeiro Museu Nacional. No entanto, o governo via outro objetivo importante nas exposições: incentivo da indústria nacional. O "desenvolvimento industrial" (shokusan kôgyô) é conhecido amplamente como a política mais importante do governo Meiji e as produções culturais foram consideradas uma das principais mercadorias. É importante entender que as exposições da época possuíam característica mais comercial do que artística. Conforme Ichikawa (2007:113), nas exposições, "com a interferência do Estado, foram examinados itens adequados / não adequados para promover a fabricação e assim elas tiveram o papel de impressionar profundamente os visitantes, pessoas comuns, mostrando a direção da modernidade".

Nessa época, o governo decidiu a primeira participação oficial na Exposição Mundial (Ban'koku Hakuran-kai) de Viena para apresentar a cultura japonesa em esfera internacional. Foi nesse momento que ocorreu a criação de uma nova palavra, "bijutsu" (belas-artes), como tradução do termo em alemão. A participação do Japão na Exposição Mundial estimulou o "japonismo", a influência da arte japonesa no mundo ocidental que tinha surgido na França na década de 1870. Essa fascinação pela arte japonesa entre os estrangeiros proporcionou aos políticos e intelectuais japoneses a conscientização sobre a relevância da própria cultura nipônica. Porém, o novo conceito de bijutsu ainda não tinha sido estabelecido amplamente entre o povo japonês. Suzuki (2005: 49) observa que esse conceito extremamente contemporâneo não chegava a enriquecer a forma do lazer ou o conhecimento do povo em geral. Segundo ele, era mais a ferramenta de reprodução do valor significativo para consolidar o novo Estado-Nação japonês construído na Era Meiji.

Com o sucesso da Exposição de Viena, aumentou a procura pelas obras artísticas e históricas. Nessa época não havia sistema legislativo de proteção de bens culturais e muitos objetos antigos ou artísticos foram vendidos, caindo nas mãos de colecionadores

7 Considera-se o ano 1872, quando foi realizada a primeira exposição no bairro de Yushima, como o ano da fundação do Museu Nacional de Tóquio. 
estrangeiros. Alguns estudiosos mencionam as políticas culturais da época. Por exemplo, Nishimura (1984: 103) aponta que houve objetivos incompatíveis na realização de exposições; promover o comércio e preservar as antiguidades. E disse que, devido à ação contraditória do governo, "ironicamente, a medida pública resultou na provocação de escoamento de bens culturais na maior escala de toda a história do país". Assim, para o governo japonês, além de promover o comércio no mercado internacional, foi necessária uma nova estratégia para prevenir a saída de obras preciosas ao exterior.

\subsection{Pesquisa de tesouros}

A abertura do país trouxe novas influências para a sociedade japonesa. Os estrangeiros especializados na área científica multidisciplinar, principalmente da Europa e dos Estados Unidos conhecidos amplamente como "Oyatoi Gaikoku-jin"(estrangeiros contratados), começaram a chegar ao Japão a partir do fim do período Edo. Entre eles, uma figura que exerceu a maior influência sobre a conceituação da política de preservação de patrimônio cultural no Japão.

O americano Ernest Francisco Fenollosa chegou ao Japão em 1878 e lecionou filosofia e economia na Universidade de Tóquio. Embora a arte não fosse sua área, uma viagem para Nara e Kyoto despertou seu interesse pela arte japonesa, tornando-o grande apreciador e colecionador de obras. Entre seus alunos da universidade, Fenollosa conheceu Kakuzo Okakura (mais conhecido pelo nome de Ten'shin Okakura), com quem compartilhou o interesse pelo reconhecimento do valor da arte japonesa. Okakura nasceu na família de um comerciante de exportação e importação em Yokohama e desde a sua infância aprendeu a falar inglês, fato que o levou a acompanhar as viagens do seu professor como intérprete. A parceria continuou depois que Okakura começou a sua carreira profissional no Ministério da Educação.

Após a publicação do Édito para a Proteção, o governo iniciou um projeto de pesquisa geral dos objetos importantes existentes no país. Anos depois, o projeto foi oficialmente iniciado com a criação de um novo órgão, o Departamento Provisório de Pesquisa de Tesouros (Rinji Hômotsu Torishirabe Kyoku) no âmbito da Secretaria da Casa Imperial. Em uma série de pesquisas, foram investigados e catalogados vários objetos e construções históricos. Consignado nesta missão, Okakura realizou viagens de pesquisa na década de 1880 junto com Fenollosa. O episódio mais conhecido dessas viagens foi uma pesquisa realizada no templo Hôryu-ji. Diferente das pesquisas realizadas por seus colegas, Okakura e Fenollosa não apenas catalogaram e fotografaram as obras históricas, mas também conseguiram abrir as portas de um dos santuários trancadas por mais de um século. Nesse santuário Yumedono, cuja abertura das portas era considerada tabu até então, foi descoberta uma estátua secreta de tamanho real do príncipe Shôtoku Taishi. Hoje a estátua é Tesouro Nacional (Figura 2), uma das obras mais conhecidas do templo e a sua exposição ao público é realizada em determinada época do ano. 


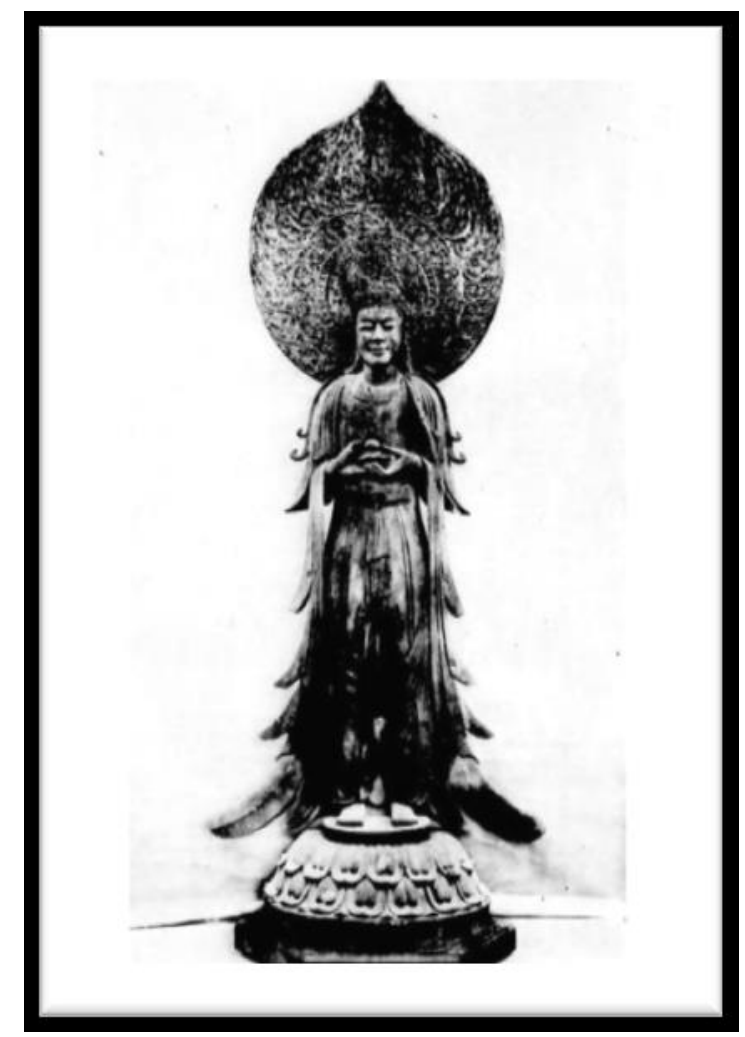

Figura 2. Guzekan'non Bosatsuzô, Hôryûji (Yumedono)

Tesouro Nacional, Século 7 (Era Asuka)

Fonte: Hôryûji Ôkagami vol. 51, Coleção Digital de Nacional Diet Library http://dl.ndl.go.jp/info:ndljp/pid/1014625

Acesso em 13/01/2018

Esse episódio explica bem a atitude dos dois apreciadores da arte. Podese considerar que foi o momento de introdução do valor artístico aos monumentos religiosos. Okakura, além de se dedicar à divulgação da arte japonesa nas exposições mundiais ao longo da sua carreira, teve importante papel na formação da política de proteção do patrimônio. Ele entregou um relatório de uma pesquisa realizada na região Kinki intitulado "Opiniões referentes à preservação de obras artísticas" (Bijutsu-hin hozon ni tsuki iken), no qual fez sugestões sobre como preservar as obras. De acordo com esse relatório, Okakura sentia que os proprietários dos objetos religiosos, na maioria das vezes, entidades budistas ou xintoístas, não reconheciam o valor artístico dos próprios bens culturais. Ele ressaltava a importância da iniciativa do governo na preservação de obras religiosas e também defendia a necessidade de auxílio financeiro público para a 
manutenção das obras nos templos. Miwa (2017: 138) acredita que esse relatório foi definitivo para direcionar o projeto de pesquisas dos tesouros e também serviu como anteprojeto para a formação da política de patrimônio do país.

Em cerca de 10 anos de atividade, o Departamento Provisório de Pesquisa de Tesouros realizou um grande trabalho de documentação. E os objetos catalogados chegaram a 215.091 itens, cujos registros foram classificados conforme a avaliação da sua importância.

\section{Criação do Tesouro Nacional}

\subsection{Rumo ao Ultranacionalismo}

Em meados da Era Meiji, o conceito de bijutsu atingiu uma tendência do nacionalismo, excluindo elementos ocidentais. Um dos exemplos significativos foi a criação de uma associação de arte Ryûchi-kai, em que se reuniram políticos e intelectuais. O grupo foi formado a fim de promover o reconhecimento da arte tradicional japonesa. Em 1882, Fenollosa recebeu um convite do grupo para dar uma palestra na qual defendeu a superioridade da pintura japonesa à pintura a óleo. Essa palestra foi publicada mais tarde com o título de "Verdadeira discussão de arte" (Bijutsu Shinsetsu) e o livro foi considerado uma "bíblia da crítica de pinturas do estilo ocidental" (Sato, 1991:158).

Alguns anos depois, Okakura foi nomeado como presidente da Escola de Arte de Tóquio (Tôkyô Bijutsu Gakkô) com 29 anos de idade. A política educativa dessa escola foi ensinar exclusivamente as técnicas tradicionais do Japão nas áreas de pintura e escultura.

Suzuki (2005) aponta que essa tendência nacionalista aparece bem na postura de Ryûichi Kuki, chefe do Departamento Provisório de Pesquisa de Tesouros que posteriormente tomou o cargo de secretário geral do Museu Imperial. Segundo Suzuki, Kuki considerava as obras de arte como "cristais", resumo de toda a história da civilização do Estado-Nação. E assim "os objetos antigos, uma vez que foram alvos de salvaguarda, passaram por seleções de acordo com a visão artística. Aqueles não considerados arte foram esquecidos, abandonados ou simplesmente chamados de 'antiguidades' " (2005: 54).

\subsection{Lei de Preservação dos Templos Antigos}

Em 1897, o governo promulgou o decreto-lei no 49, a "Lei de Preservação de Antigos Templos Budistas e Xintoístas" (Koshaji Hozonhô), a primeira lei abrangente da questão patrimonial nacional. A lei era bastante inovadora comparado com o Édito principalmente em dois pontos: determinava a criação do tombamento de Tesouro Nacional (Kokuhô) e de Edifícios Especiais para a Proteção (Tokubetsu Hogo Kenzôbutsu) e a obrigação de atender à chamada para exposição dos bens tombados nos museus públicos. E na condição de que a obrigação fosse cumprida, 
garantiu que os proprietários dos bens tombados recebessem subsídios financeiros para sua manutenção e restauração. Na sua $4^{\mathrm{a}}$ cláusula, determina:

Quanto às construções de templos budistas e xintoístas e aos tesouros móveis, quando reconhecido seu valor pelos testemunhos da história nacional ou pelas obras de valor referencial artístico, receberão certificado de Edifícios Especiais para a Proteção ou Tesouro Nacional através de consulta à Comissão para a Preservação de Antigos Templos Budistas e Xintoístas e aprovação do Ministro de Assuntos Internos.

Ao mesmo tempo da publicação da lei, foi formado o órgão executivo "Comissão para a Preservação de Antigos Templos Budistas e Xintoístas" (Koshaji Hozonkai) na qual se reuniram os mesmos membros do Departamento Provisório de Referências de Tesouros, entre eles, Ten'shin Okakura sob a direção de Ryûichi Kuki.

Como o próprio nome indica, a lei objetivava a proteção das propriedades de templos e não incluía propriedades particulares. E a sua cláusula define claramente a importância do valor "artístico" dos objetos religiosos. Nishimura (1984) fez uma observação interessante sobre o conceito dessa lei. Na sua pesquisa sobre o tombamento das construções, afirmou:

A proteção de edificações foi estabelecida com a lei. Porém, as "construções" nesse caso devem ser entendidas como "sistema" e não como "obra". Em outras palavras, o que deveria ser protegido na época eram instituições religiosas e, para isso, era necessário preservar suas estruturas, que são construções. (1984:108)

Nota-se que os objetos e as construções recebiam designação diferenciada.

Apenas bens móveis foram tombados como Tesouro Nacional. Posteriormente, a designação foi unificada em 1929 (Era Showa), com a publicação de uma nova lei, a "Lei de Preservação de Tesouro Nacional". Durante todo esse tempo, os Tesouros Nacionais eram exclusivamente bens móveis.

\section{Considerações finais}

Pode-se considerar os três importantes fatores na formação do Tesouro Nacional. Em primeiro lugar, a preservação de bens culturais iniciou-se no Japão para proteger propriedades dos templos budistas, como estátuas e pinturas religiosas que sofriam destruição no início da Era Meiji. A primeira norma jurídica anunciada nessa época, apesar de sua insuficiência como política pública, como Dangi (1999: 8) também ressalta, tem a sua importância significativa histórica. 
O segundo ponto importantíssimo foi a introdução da visão artística aos objetos histórico e religiosos. Com a criação de uma nova palavra bijutsu, as propriedades dos templos começaram a ser reconhecidas pelo seu valor artístico. Para Ogawa (2001: 113) foi o momento de "redefinição sistemática dos objetos religiosos dentro de nova categoria de arte". Personalidades como Okakura e Fenollosa tiveram influência definitiva nessa transformação, principalmente na orientação do projeto de pesquisa dos tesouros. Os objetos estudados no projeto foram classificados conforme a sua importância artística e histórica. Como Miwa (2017: 154) aponta, a avaliação feita nessa pesquisa influenciou posteriormente na seleção dos Tesouros Nacionais.

Por último, é necessário lembrar que as políticas de proteção de bens culturais e de desenvolvimento de indústria foram desenvolvidas juntamente no Japão. O elevado interesse pela arte japonesa resultou ao escoamento de obras preciosoas ao exterior e consequentemente, necessitou protegé-las pela lei, através o ato de tombamento de peças importantes.

Assim, na Era Meiji, em 30 anos depois da publicação do Édito, os objetos antigos foram reconhecidos, selecionados e chegaram a ter designação de Tesouro Nacional e o seu conceito é definido como "tesouro de todo o povo japonês" ${ }^{8}$ nos dias atuais.

\section{Referências Bibliográficas}

AOYAGI, N.; IWATSUKI, N.; FUJIOKA, Y. Bunkazaihogohô seiteigo no kokuhô kenzôbutsu shiteihoushin to sengo "kokuhô" gainen no keisei. Nihon Kenchikugakkai Keikakukei Ronbunshû, v. 678, p. 1997-2005, 2012.

DANGI, Kazuyuki. Bunkazai Hogohô Seitei Izen: Bunkazai no kyôtsû rikai no tameni. Housei Shigaku, v. 52, p.4-11, 1999.

FONSECA, Maria Cecília Londres. O Patrimônio em processo : trajetória da política federal de preservação no Brasil. 3. ed. Rio de Janeiro: Editora UFRJ, 2009.

ICHIKAWA, Yuki. "Kôgei” oyobi “Shokunin" gainen no rekishiteki hen'sen ni kan'suru kôsatsu. Takasaki Keizai Daigaku Chiiki Seisaku Kenkyû, v. 10, p.109-128, 2007.

JAPÃO. Édito (1871). Koki Kyûbutsu Hozon Kata. [Édito para a Preservação de Antiguidades e Objetos Antigos]. Gabinete Ministerial, 1871.

JAPÃO. Lei no 49, de 10 de junho de 1897. Koshaji Hozonhô.[Lei de Preservação de Antigos Templos Budistas e Xintoístas]. Gabinete Ministerial, 1897.

KUSUMOTO, Machiko. Okakura Ten'sin ni miru ban'koku hakuran'kai to ibunka kôryû. Gengo Bunka, v.9, p.71-80, 2001.

MIWA, Shizuka. Rinji Zenkoku Hômotsu Chôsa-kyoku no katsudô to sono eikyô: hakubutsukan to sono shûhen no dôkô kara. Ochanomizu Shigaku. 2017. Disponível

8 Artigo 27-2, Bunkazai Hogohô (Lei de Proteção de Bens Culturais ), 1950. http://www.tcp-ip. or.jp/ syaraku/hogohou.htm. Acesso em 13/01/2018. 
em: http://133.65.151.33/ocha/bitstream/10083/61390/1/60_5_p.115-162.pdf. Acesso em: $18 / 01 / 2018$.

NAMIMATSU, Nobuhisa. Kin'dai nihon ni okeru hakubutsu-kan seisaku no ten'kai. Kyoto Sangyô Daigaku Nihon Bunka Kenkyu-jo Kiyô, v.21, p.252-291, 2016.

NISHIKAWA, Kotaro. Fukuzawa Yukichi to bunkazai hogo. Booklet, v.17, p.48-56, 2009.

NISHIMURA, Yukio. Kenzô-butsu no hozon ni itaru Meiji zen'ki no bunkazai hogo gyôsei no ten'kai. Nihon Ken'chiku Gakkai Ron'bun Houkoku-shû, v.340, P.101-110, 1984.

OGAWA, Nobuhiko. Takaramono, Kokuhô, Bunkazai: mono to shôchô no politikusu/poetikusu. In: Bunka no Shakaigaku : kioku, , media, shin'tai. Kyoto: Bunri kaku, 2009. p.71-89.

OGINO, Masahiro. Bunka isan heno shakaigakuteki apurôchi. In: Bunka isan no Shakaigaku : rûburu bijutsu-kan kara genbaku dômu made. Tóquio: Shin'yo-sha, 2002. P.1-33.

SAITSU, Yumiko. Sekai isan to nihon no bunka isan. 21 seiki Higashi Ajia Shakaigaku, v.5, p. 117-130, 2013.

SATO, Michinobu. Meiji bijutsu to bijutsu gyôsei. Bijutsu Kenkyû, v. 350, p. 152-165, 1991.

SUZUKI, Hiroyuki. Meiji-ki ni okeru mono no kachi to Ninagawa Noritane. Meiji Shôtoku Kinen Gakkai Kiyô, v.41, p.44-62, 2005.

TANAKA, Migaku. Gendai shakai to bunka isan. In: AMINO. Y.; GOTO, M.; IINUMA, K.(org). Hito to Kankyô to Bunka Isan : 21 seiki ni nani wo tsutaeruka. Tóquio: Yamakawa shuppan-sha, 2000. P. 4-20.

WADA, Katsuhiko. Bunkazai seisaku no hen'sen. In: KAWAMURA, Tsuneaki (org.). Bunkazai Seisaku Gairon. Tóquio: Tôkai Daigaku shuppan-kai, 2002. P.39-72. 